\title{
The Threshold Effect of FDI on Regional Innovation Capability- From the Perspective of Intellectual Property Protection
}

\author{
Li Wencong ${ }^{1, *}$ \\ ${ }^{1}$ School of Economics and Management, Beijing Jiaotong University, Beijing, China
}

\begin{abstract}
As one of the important channels of technology spillover, foreign direct investment (FDI) has a significant impact on regional innovation capability, which is restricted by the intensity of intellectual property protection. In order to explore the relationship between these three factors, this paper constructs a nonlinear threshold regression model based on China's provincial panel data from 2009 to 2018, and empirically analyzes the threshold effect of FDI on regional innovation capability with the intensity of intellectual property protection as the threshold variable. The results show that the impact of FDI on regional innovation capability has a significant single threshold effect of intellectual property protection intensity. Only when the intensity of intellectual property protection remains near the threshold value, can FDI promote regional innovation capability to the greatest extent.
\end{abstract}

\section{Introduction}

Throughout the history of human development, innovation is an inexhaustible driving force for the development of a country and a nation. In the decades since the reform and opening up, China has successfully achieved leapfrog development, the secret of which lies in technological innovation and industrial upgrading. In the context of economic globalization, innovation has increasingly become a key factor for a country to enhance its international competitiveness and prestige.

Under the condition of open economy, modern economic growth theory holds the view that innovation comes from two ways, one is independent innovation which is brought by $\mathrm{R} \& \mathrm{D}$, the other is introduction innovation and imitation innovation caused by FDI. Especially for developing countries, FDI has become an important channel for them to introduce advanced technology and enhance their innovation capability.

One of the purposes for China to vigorously promote FDI is to rapidly improve China's innovation capability and realize technological progress through international technology spillover. However, in this process, the effect of FDI on China's innovation capability is affected by many factors, including the intellectual property protection system. In recent years, intellectual property protection has become an important topic, especially since China signed TRIPs, it has become more and more important to establish a scientific intellectual property protection system in China.

Most of the existing studies are carried out from two aspects, one is the impact of FDI on regional innovation capability, the other is the impact of intellectual property protection intensity on the promotion of regional innovation capability by FDI.
Scholars have different opinions on whether FDI can promote regional innovation capability. Tang et al. (2018) analyzed the impact of FDI on innovation by taking the service industry as the research object, and the results showed that FDI significantly promoted the innovation capability of regional enterprises through learning effect and competition effect ${ }^{[1]}$. There are also some scholars believe that the technology spillover effect of FDI is influenced by some factors. For example, the level of economic development, the level of financial development, the degree of foreign trade openness, the regional economic structure. However, some scholars believe that FDI can not improve the innovation capability of the host country. Haddad and Harrison (1993) believed that FDI could not promote regional technological progress, but inhibited its innovation ${ }^{[2]}$.

Another kind of research focuses on the impact of intellectual property protection intensity on FDI technology spillover effect. Globerman et al. (2000) showed that FDI under the constraint of intellectual property protection system would significantly promote the occurrence of technology spillover effect ${ }^{[3]}$. However, Maskus (2000) believed that the relationship between the intensity of intellectual property protection and technological innovation was not a simple linear relationship, but an inverted " $U$ " relationship ${ }^{[4]}$. Lerner (1995) found that in the condition of weak intellectual property protection system, strengthening the intensity was conducive to the regional innovation. But if the intellectual property protection intensity was too strong, the opposite result would appear ${ }^{[5]}$.

In conclusion, most existing studies show that FDI has an impact on regional innovation capability, and this impact is related to the intensity of intellectual property protection. However, the existing researches have the

* Corresponding author: 269937735@qq.com 
following disadvantages: First, most of these conclusions are biased towards strict or loose intensity of intellectual property protection. Second, the existing studies pay less attention to the mechanism of FDI's impact on regional innovation capability. Third, some scholars point out the conclusions from the reality of foreign countries, but these conclusions are not based on the situation in China, so they can not explain the problems in China. These disadvantages provide inspiration for this paper.

\section{Theoretical analysis and research hypothesis}

\subsection{The mechanism of FDI influencing regional innovation}

FDI is a common channel of international technology diffusion, which mainly improves regional technological innovation capability through competition effect, learning effect and linkage effect.

First, the competition effect. The entry of transnational corporations often leads to the intensification of competition. On the one hand, in order to compete in the market and maintain market share, local enterprises must reduce production costs, improve efficiency and product quality through technological innovation. On the other hand, the competition between transnational corporations and local enterprises also includes the competition of resources. Transnational corporations will attract regional high-quality talents with more favorable treatment, which hinders the progress of independent innovation of local enterprises. Therefore, from the perspective of competition effect, it is still difficult to conclude the role that FDI plays in the innovation of local enterprises.

Second, the learning effect. The subsidiaries of transnational corporations produce in the host country. In order to achieve the target task, they will employ local labors. If the employees leave after mastering the technology, they will bring positive learning effect to the local enterprises. The subsidiaries of transnational corporations also create technology spillover effect for the local enterprises, forming the FDI spillover effect with staff turnover as the carrier. In addition, the subsidiaries of transnational corporations can also realize learning spillover during business operations, or learn and imitate advanced technologies of transnational corporations through product exchanges, scientific research cooperation and other ways. In this process, a path of "learning - imitation - innovation" has been formed.

Third, the linkage effect. When transnational corporations enter the host country, they will establish connections with the upstream and downstream industrial chains of local enterprises, and outsource some intermediate products to other companies. The subsidiaries purchase intermediate products and services from local suppliers resulting in backward linkage, and supply products and services for downstream enterprises resulting in forward linkage, which forms the vertical technology spillover. The backward linkage plays a positive role by improving product standards, while the forward linkage promotes the improvement of enterprise innovation capability by improving the quality of intermediate products and joint development. Based on these, this paper puts forward the following hypothesis 1 :

Hypothesis 1: FDI can promote regional innovation capability through competition effect, learning effect and linkage effect.

\subsection{The impact of the intensity of intellectual property protection on the innovation effect of FDI}

The intellectual property protection system is an authoritative legal protection system for scientific and technological innovation achievements. With the deepening of international opening pattern and the complex international trade environment, the trade frictions caused by intellectual property are increasing day by day, which urgently requires the improvement of the intellectual property protection system.

On the one hand, strengthening the intensity of intellectual property protection can effectively protect the innovation achievements, reduce the free rider problem, solve the problem of technological externality, get rid of the concerns of investment enterprises, and facilitate the technical communication and business cooperation between transnational corporations and local enterprises. On the other hand, strengthening the intensity of intellectual property protection will increase the cost of imitation innovation of local enterprises, inhibit the enthusiasm of regional technological innovation, and form the monopoly position of foreign investors. However, if the intellectual property protection is too loose, the technology of foreign-invested enterprises will be easily imitated. They will lose their competitive advantage, which will weaken their investment willingness. Based on these, this paper puts forward the following hypothesis 2 :

Hypothesis 2: The impact of FDI on regional innovation capability is limited by the threshold effect of intellectual property protection intensity.

\section{Model and variable selection}

From the previous theoretical analysis, we can see that there may be a non-linear relationship between FDI and regional innovation capability under the influence of intellectual property protection intensity and other factors. Therefore, this paper uses the non-linear panel regression model proposed by Hansen (1999), namely "threshold regression model", and takes the threshold value as an unknown variable into the model to construct a piecewise function, so as to test the role of intellectual property protection intensity in the impact of FDI on regional innovation capability. Referring to Hansen's (1999) "threshold regression model" and the existing references, this paper introduces other controlled variables, and constructs a single threshold panel model with the intensity of intellectual property protection as the threshold variable, regional innovation capability as the explained variable, and FDI as the core explanatory variable: 


$$
\begin{gathered}
\operatorname{lninno}_{i t}=u_{i}+\alpha_{1} \operatorname{lnpgdp}_{i t}+\alpha_{2} \operatorname{lnfin}_{i t}+ \\
\alpha_{3} \operatorname{lnopen}_{i t}+\alpha_{4} \operatorname{lngov}_{i t}+\alpha_{5} \operatorname{lnhum}_{i t}+ \\
\alpha_{6} \operatorname{lntec}_{i t}+\beta_{1} \operatorname{lnfdi}_{i t} I\left(\operatorname{lnipr}_{i t} \leq \gamma\right)+ \\
\beta_{2} \operatorname{lnf} f i_{i t} I\left(\operatorname{lnipr}_{i t}>\gamma\right)+\varepsilon_{i t}
\end{gathered}
$$

Multi-threshold panel model (take double threshold as an example):

$$
\begin{gathered}
\text { lninno }_{i t}=u_{i}+\alpha_{1} \operatorname{lnpgdp}_{i t}+\alpha_{2} \operatorname{lnfin}_{i t}+ \\
\alpha_{3} \text { lnopen }_{i t}+\alpha_{4} \operatorname{lngov}_{i t}+\alpha_{5} \operatorname{lnhum}_{i t}+ \\
\alpha_{6} \operatorname{lnte}_{i t}+\beta_{1} \operatorname{lnfdi}_{i t} I\left(\text { lnipr }_{i t} \leq \gamma_{1}\right)+ \\
\beta_{2} \operatorname{lnfdi}_{i t} I\left(\gamma_{1}<\operatorname{lnipr}_{i t} \leq \gamma_{2}\right)+ \\
\beta_{3} \ln f d i_{i t} I\left(\operatorname{lnipr}_{i t}>\gamma_{2}\right)+\varepsilon_{i t}
\end{gathered}
$$

Where, $i$ represents the province, $t$ represents the year, and $u_{i}$ represents the fixed effect. $I(\cdot)$ is the indicator function, which is 1 if the condition in parentheses is true, and 0 if the condition is not true. $\gamma$ represents the threshold value to be estimated, and $\varepsilon_{i t}$ represents the random disturbance term.

Considering the huge differences in the development of different regions in China, this paper uses provincial panel data for empirical analysis. Due to the Outline of national intellectual property strategy was promulgated in 2008, the intensity of intellectual property protection in various regions had been greatly strengthened, so the sample time is from 2009 to 2018.

1. Explained variable

Regional innovation capability (inno). Although the final result of innovation is to increase the sales revenue of products, compared with it, patents represent the level of technological innovation activities and scientific research output in a region, so the number of granted patents is more intuitive and the data accuracy is higher. Therefore, this paper uses the number of granted patents owned by each province to measure the regional innovation capability.

\section{Explanatory variable}

Foreign direct investment $(f d i)$. This paper uses the actual amount of foreign direct investment used by each province of China over the years to measure FDI.

3. Threshold variable

The intensity of intellectual property protection (ipr). Referring to the method of Dai (2014), the specific calculation method of intellectual property protection intensity is as follows:

$$
\text { ipr }_{i t}=1+\frac{\frac{\text { crime }_{i t}}{\text { adpatent }_{i t}}}{\frac{\sum \text { crime }_{i t}}{\sum \text { adpatent }_{i t}}}
$$

Where, crime $_{i t}$ represents the number of law enforcement cases about intellectual property in region $i$ in year $t$, adpatent $t_{i t}$ represents the number of granted patents, $\frac{\sum \text { crime }_{i t}}{\sum \text { adpatent }_{i t}}$ represents the proportion of the number of law enforcement cases about intellectual property in the number of granted patents in the country in year $t$.

4. Controlled variables

(1) Economic development level ( $p g d p)$. This paper uses the Real GDP per capita of each province over the years to measure the economic development level.
(2) Financial development level (fin). It is measured by the ratio of loan balance of financial institutions in each province to regional GDP.

(3) The degree of foreign trade openness (open). This paper uses the total import and export of each province over the years to measure the degree of foreign trade openness.

(4) Government influence (gov). It is measured by the proportion of financial expenditure on science and technology of each province in the total financial expenditure of each province over the years.

(5) Human capital (hum). hum $_{i t}=6$ prim $_{i t}+$ 9 mid $_{i t}+12$ high $_{i t}+16$ uni $_{i t}$. Where, prim $_{i t}$, mid $_{i t}$, $h i g h_{i t}, u n i_{i t}$ represent the proportion of the population with education at primary school, junior high school, senior high school, college or above in the population above 6 years old in each province.

(6) Technological level (tec). This paper uses the turnover of technology markets in each province over the

\begin{tabular}{|c|c|c|c|c|c|c|}
\hline Threshold & RSS & MSE & Fstat & Prob & Crit10 & Crit5 \\
\hline Single & 5.9486 & 0.0313 & 22.96 & 0.0433 & 18.5625 & 21.3988 \\
\hline Double & 5.7636 & 0.0303 & 6.10 & 0.6200 & 15.0885 & 19.0874 \\
\hline Triple & 5.6497 & 0.0297 & 3.83 & 0.7067 & 11.9304 & 15.1043 \\
\hline
\end{tabular}
years to measure the technological level.

\section{Empirical analysis}

Stata is used to test whether the model has threshold effect. In order to facilitate the operation, the triple threshold model is first implemented to obtain the significance test results of threshold effect as shown in Figure 1. $\mathrm{P}=0.7067$,

\begin{tabular}{|c|c|c|c|c|c|c|c|}
\hline Threshold & RSS & MSE & Fstat & Prob & Crit10 & Crit5 & Crit1 \\
\hline Single & 5.9486 & 0.0313 & 22.96 & 0.0533 & 19.0538 & 23.9993 & 34.6709 \\
\hline Double & 5.7636 & 0.0303 & 6.10 & 0.5900 & 14.7239 & 18.2506 & 27.1170 \\
\hline
\end{tabular}
it is obvious that the result is not significant under the triple threshold effect, and then the double threshold effect test is carried out.

Fig. 1. Significance test of triple threshold effect

The result is shown in the figure below, $\mathrm{P}=0.59$, the result is not significant, indicating that there is no double threshold effect, and then the single threshold effect test is carried out.

Fig. 2. Significance test of double threshold effect

$\mathrm{P}=0.03$, the single threshold effect is significant, so this paper selects the single threshold model for analysis. The single threshold effect is significant, which indicates that the impact of FDI on regional innovation capability will be different because of the differences in the intensity of intellectual property protection. 
Threshold effect test (bootstrap $=300)$ :

\begin{tabular}{r|rrrrrrr}
\hline Threshold & RSS & MSE & Fstat & Prob & Crit10 & Crit5 & Crit1 \\
\hline Single & 5.9486 & 0.0313 & 22.96 & 0.0300 & 17.8338 & 21.3942 & 27.2511 \\
\hline
\end{tabular}

Fig. 3. Significance test of single threshold effect

The threshold value is estimated and the confidence interval is calculated. The threshold value is 0.0112 , under the $95 \%$ confidence level, and the confidence interval of the threshold value is $(0.0105,0.0113)$.

\begin{tabular}{r|rrr}
\multicolumn{4}{l}{ Threshold estimator $($ level $=95):$} \\
\hline model & Threshold & Lower & Upper \\
\hline Th-1 & 0.0112 & 0.0105 & 0.0113 \\
\hline
\end{tabular}

Fig. 4. Threshold value and confidence interval

Draw the trend graph of single threshold function. It can be seen that the single threshold value 0.0112 is the lowest point in LR graph. At $95 \%$ confidence level, the values of threshold confidence interval are below the dotted line, which indicates that the threshold estimation is true and effective.

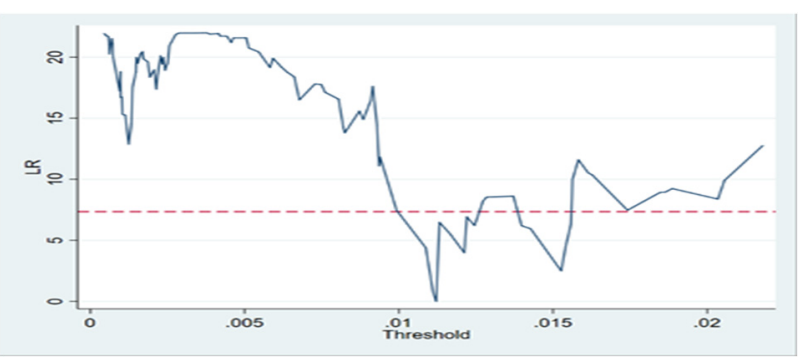

Fig. 5. Single threshold LR graph

Then the parameters of the single threshold model are estimated. In Figure 6, we focus on the regression coefficient of lnfdi. 0 indicates the impact of FDI on regional innovation capability when the threshold variable is lower than the threshold value. At this time, the coefficient of $\operatorname{lnfdi}$ is -0.02 , and it does not pass the significance test, which indicates that FDI can not significantly promote regional innovation capability. 1 indicates the impact of FDI on regional innovation capability when the threshold variable is higher than the threshold value. The coefficient of $\operatorname{lnfdi}$ is -0.03 at this time, and it does not pass the significance test, which indicates that FDI can not significantly promote regional innovation capability. To sum up, it shows that only when the intensity of intellectual property protection remains at an appropriate level, that is, when the intensity of intellectual property protection is at the threshold level, FDI can significantly promote regional innovation capability. The reason for this phenomenon is that when the intensity of intellectual property protection is too low, the advanced technology of transnational corporations is easy to be imitated by local enterprises. So they will reduce the investment in the region, and reduce the possibility of technology spillover, which will hinder the improvement of regional innovation capability. When the level of intellectual property protection is too high, the advanced technology of transnational corporations is difficult to spread out, and the imitation cost of local enterprises is greatly increased, which will reduce their enthusiasm of innovation.

Then observe the parameter estimation results of the controlled variables. The economic development level and the financial development level have a significant positive impact on the improvement of regional innovation capability. Although the degree of foreign trade openness, the government influence and the technological level can also have a positive impact on regional innovation, this effect is not significant. But the human capital has a negative impact on regional innovation capability, which is contrary to the expected results.

\begin{tabular}{|c|c|c|c|c|c|c|}
\hline Ininno & Coef. & $\begin{array}{c}\text { Robust } \\
\text { Std. Err. }\end{array}$ & $\mathrm{t}$ & $P>|t|$ & [958 Conf. & Interval] \\
\hline Inpgdp & 1.530098 & .3101445 & 4.93 & 0.000 & .8809577 & 2.179238 \\
\hline lnfin & 1.225995 & .2032516 & 6.03 & 0.000 & .8005843 & 1.651405 \\
\hline Inopen & .2665087 & .126251 & 2.11 & 0.048 & .0022624 & .530755 \\
\hline lngov & .1066851 & .158267 & 0.67 & 0.508 & -.2245714 & .4379417 \\
\hline 1nhum & -.86432 & 1.161881 & -0.74 & 0.466 & -3.296164 & 1.567524 \\
\hline Intec & .0446022 & .0603777 & 0.74 & 0.469 & -.0817699 & . 1709742 \\
\hline \multicolumn{7}{|l|}{ cat $\neq c . \operatorname{lnfdi}$} \\
\hline 0 & -.0208092 & .0741459 & -0.28 & 0.782 & -.1759984 & .1343801 \\
\hline 1 & -.0332828 & .0745384 & -0.45 & 0.660 & -.1892935 & .1227278 \\
\hline _cons & -5.473808 & 2.326172 & -2.35 & 0.030 & -10.34254 & -.6050734 \\
\hline
\end{tabular}

Fig. 6. Parameter estimation results of threshold model

Finally, this paper uses the number of patent applications instead of the number of granted patents to recalculate the intensity of intellectual property protection, and uses it as a threshold variable for robustness test. It is consistent with the previous results, indicating that the regression model is robust.

\section{Conclusions}

The results show that only when the intensity of intellectual property protection remains near the single threshold value, the promotion effect of FDI on regional innovation capability will be significant. At the same time, the economic development level and the financial development level have a significant positive impact on the improvement of regional innovation capability. These conclusions are of great significance for China to make more efficient use of FDI to promote regional innovation.

Based on the results of this study, the following policy suggestions are put forward: First, give full play to the technology spillover effect of foreign direct investment. Second, formulate a reasonable intellectual property protection system. Third, build the perfect sci-tech finance system. Fourth, insist on the principle of selfreliance and self-improvement in science and technology, and create new advantages for development in an allround way.

\section{References}

1. Tang, Y. H. (2018) Do Chinese Service Enterprises Obtain Innovation from FDI in Service Industry. J. Journal of Beijing Normal University, 3: 130-143. 
2. Haddad, M., and A. Harrison.. (1993) Are There Positive Spillovers from Direct Foreign Investment? Evidence from Panel Data for Morocco. J. Journal of Development Economics, 42: 51-74.

3. Globerman, S., A. Kokko, and F. Sjoholm. (2000) International Technology Diffusion: Evidence from Swedish Patent Data. J. Kyklos, 53: 17-38.

4. Maskus, K. E. (2000) Intellectual Property Rights in the Global Economy. Peterson Institute for Peterson Institute, Washington.

5. Lerner, J. (1995) Patenting in the Shadow of Competitors. J. Journal of Law and Economics, 38: 463-495. 